\title{
Association of Periodontal Diseases and Liver Fibrosis in Patients With HCV and/or HBV infection
}

\author{
Yumiko Nagao $^{1, *}$; Yuji Kawahigashi ${ }^{1}$; Michio Sata $^{2}$ \\ ${ }^{1}$ Department of Digestive Disease Information and Research, Kurume University School of Medicine, Kurume, Fukuoka, Japan \\ $2_{2}$ Research Center for Innovative Cancer Therapy, Kurume University School of Medicine, Kurume, Fukuoka, Japan \\ *Corresponding Author: Yumiko Nagao, Department of Digestive Disease Information and Research, Kurume University School of Medicine, Kurume, Fukuoka, 830-0011, Japan. Tel: \\ +81-942317902, Fax: +81-942317820, E-mail: Nagao Y: nagao@med.kurume-u.ac.jp
}

Received: September 3, 2014; Revised: October 6, 2014; Accepted: November 8, 2014

\begin{abstract}
Background:Periodontal disease and systemic health are closely associated. However, there is no data supporting the association between periodontal disease and patients with liver diseases associated with hepatitis C virus (HCV) and/or hepatitis B virus (HBV) infection.

Objectives: The aim of this study was to evaluate the association between periodontitis and progression of liver diseases in patients with HCV and/or HBV infection.

Patients and Methods: In this retrospective study, 351 patients with HCV- and/or HBV-related liver diseases underwent screening for periodontal disease using the Salivaster® salivary occult blood test from February 2010 to June 2014. Furthermore, we examined the prevalence of fimbrillin ( fimA) genotype of Porphyromonas gingivalis (P. gingivalis) in 28 HCV-infected patients visited at our hospital between January 2013 and June 2014. P. gingivalis with fimA genotype with types I to V was further detected using a PCR method.

Results: Of 351 patients, 76 patients (group 1) had a strong positive result for salivary occult blood test and 275 patients (group 2) had weak positive or negative test results. Significant factors between the groups were obesity, level of AST,ALT, LDH, ALP,Alb, D.Bil, T.cho, AFP, platelets (PIt), IRI, HOMA-IR, current interferon (IFN) treatment and the daily frequency of tooth brushing. Between-groups analysis indicated that total protein (T.pro) level and liver fibrosis were significant factors. According to multivariate analysis, five factors were associated with periodontal disease as Plt count below 80000 , brushing teeth only once a day, current IFN treatment, aged 65 years or older and obesity. The adjusted odds ratios for these five factors were 5.80, 3.46, 2.87, 2.50 and 2.33, respectively, and each was statistically significant. Twentyeight saliva specimens had positive results for P. gingivalis with fimA genotype types I to $\mathrm{V}$. The prevalence of fimA genotype II was higher in 14 patients with liver cirrhosis or a history of hepatocellular carcinoma treatment (group B, 50.00\%) than 14 patients with only hepatitis $C$ (group A, 21.43\%).

Conclusions: Periodontitis might be associated with progression of viral liver disease; hence, controlling oral disease is essential for the prevention and management of liver fibrosis.
\end{abstract}

Keywords:Periodontal Disease; Hepatitis C virus; Hepatitis B Virus; Interferon; Fibrosis; Porphyromonas gingivalis; Fimbrillin

\section{Background}

The incidence of hepatocellular carcinoma (HCC) is increasing worldwide. In Japan, about 35000 deaths are reported due to HCC annually (1). In Japan, patients infected with hepatitis C virus (HCV) are older than those in other countries $(2,3)$. Therefore, for patients with a high risk of developing HCC, it is necessary to implement a multifaceted treatment plan including nutritional interventions, exercise and measures to promote overall general wellness in addition to drug therapy. Therapy using interferon (IFN), an antiviral agent, reduces the rate of occurrence of HCC and improves long-term prognosis (4-6). Whereas, it is shown that periodontal disease even minimal chronic inflammation of the periodontal tissue, is associated with various systemic diseases such as cardiovascular disease and type II diabetes mellitus (DM), as well as low preterm birth-weight in children (7-9). Periodontitis is the most common chronic infection in adults and caused by bacteria encountered in subgingival plaque. The most important and prevalent anaerobic gram-negative bacteria in subgingival area are Actinobacillus actinomycetemcomitans (A. actinomycetemcomitans), Porphyromonas gingivalis (P. gingivalis), Prevotella intermedia (P. intermedia) and Tannerella forsythensis (T. forsythensis). These bacteria play an important role in the onset and subsequent development of periodontitis, participating in the formation of periodontal pocket, connective tissue destruction, and alveolar bone resorption by means of an immunopathogenic mechanism (10). Dental plaque is a naturally occurring microbial layer or biofilm, which develops on the tooth surface. Biofilm formation is an important step in the etiology of periodontal diseases. Biofilms are particularly important in the oral cavity where the primary colonizers, which attach to oral surfaces, can enhance colonization of other bacteria which are themselves poor colonizers (11). Periodontal bacterial DNA of $P$. gingivalis has been detected

Copyright (C) 2014, Kowsar Corp. This is an open-access article distributed under the terms of the Creative Commons Attribution-NonCommercial 4.0 International License (http://creativecommons.org/licenses/by-nc/4.0/) which permits copy and redistribute the material just in noncommercial usages, provided the original work is properly cited. 
in atherosclerotic lesions of aortic tissues using various polymerase chain reaction (PCR) techniques (12). P. gingivalis, a gram-negative oral anaerobe, is strongly associated with chronic adult periodontitis (13). The major structural subunit protein of fimbriae, FimA (fimbrillin), mediates the invasion of gingival epithelial cells by $P$. gingivalis (14). The FimA-coding gene, fimA, was classified into several genotypes (15) and their correlations with severity of periodontal diseases were investigated $(15,16)$. There are six variants of $P$. gingivalis fimA gene (types I to $V$ and Ib). It was demonstrated that bacterial clones with types II, IV or Ib fimA are invasive, whereas those with types I, III or V fimbriae are noninvasive $(15,16)$. It was recently reported that infection with high-virulence $P$. gingivalis might be a risk factor of development and progression of non-alcoholic fatty liver disease (NAFLD) and nonalcoholic steatohepatitis (NASH) (17). However, there are no data to support the association between periodontal disease and patients with liver diseases associated with $\mathrm{HCV}$ and/or hepatitis B virus (HBV) infection.

\section{Objectives}

In this study, we retrospectively examined the impact of oral environment on liver disease state, especially whether the presence of periodontal disease has an influence on liver disease progression, and we assessed the effect of IFN therapy in patients with HCV-and/or HBV-related liver diseases.

\section{Patients and Methods}

\subsection{Patients}

\subsubsection{Study 1}

A total of 433 consecutive patients had checkups for oral mucosal diseases at the Oral Medicine clinic of the Digestive Diseases Center at Kurume University Hospital, Japan from February 1, 2010 to June 17, 2014. At the clinic, each patient was examined by physicians and an oral surgeon. Of 433 subjects, nine were edentulous and had been using a complete denture, and 34 subjects did not undergo a salivary occult blood test to screen the presence of periodontal disease. After exclusion of subjects with normal livers (20 patients) and subjects who had liver disease unrelated to HCV-and/or HBV infection, such as those with autoimmune liver disease (totally 19 patients; fatty liver: 10 cases; primary biliary cirrhosis: 4 cases; autoimmune hepatitis and HCC: 1 case; NASH: 1 case; non-B, nonC liver cirrhosis (LC): 1 case; non-B, non-C LC and HCC: 1 case; drug-induced liver injury: 1 case), 351 patients were enrolled in this study (Figure 1).

\subsubsection{Study 2}

The prevalence of fimA fimbriae genotype was assessed in $28 \mathrm{HCV}$-infected patients visited at our hospital be- tween January 2013 and June 2014. HBs antigen-positive patients were excluded as subjects.

\subsection{Examination of Oral Mucosal Disease}

Subjects were asked regarding their daily frequency of tooth brushing. Mucosal examination was performed using a headband fiber (50-100-10, Daiichi Medical Co., Ltd.) with a brightness of 34000 luces for mucosal examination. Oral biopsy was performed on some patients.

\subsection{Salivary Occult Blood Test}

Salivary occult blood test examines the presence of blood derived mainly from the gingival tissue and released into the saliva. We examined the presence of periodontal disease as an indicator of periodontitis using the Salivaster® reagent-based test (Showa Yakuhin Kako Co. LTD, Tokyo, Japan) $(18,19)$. The Salivaster@ is a colorimetric test based on a catalytic reaction of hemoglobin in saliva inducing the formation of different colors ranging from yellow to dark blue. The principle of color reaction is similar to the test for blood in urine, but was developed for the particular viscosity of saliva. The occult blood reaction is classified according to three levels: double positive $(++)$, positive $(+)$ and negative $(-)$. This method is reported to have a sensitivity of $75.9 \%$ and specificity of 90.5\% to detect gingival inflammation (20).

\subsection{Measurement of Body Weight}

Obesity was defined as a body mass index (BMI) equal to or more than $25 \mathrm{~kg} / \mathrm{m}^{2}$.

\subsection{Serological Assays}

All subjects were tested for red blood cell (RBC) count, white blood cell (WBC) count, platelet (Plt) count, hemoglobin (Hb), insulin resistance index (IRI), zinc (Zn) level, fasting blood glucose (FBS), and HbA1c, and for the following liver function tests: serum alanine aminotransferase (ALT), aspartate aminotransferase (AST), lactate dehydrogenase (LDH), alkaline phosphatase (ALP), prothrombin time (PT), total bilirubin (T.Bil), direct bilirubin (D.Bil),

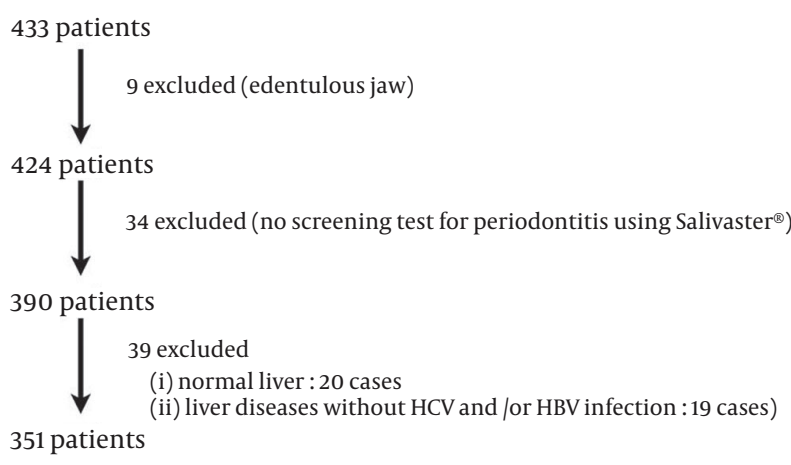

Figure 1. Schema for the Subjects 
Nagao Yetal.

total cholesterol (T.cho), total protein (T.pro), albumin (Alb) and C-reactive protein (CRP). HOMA-IR formula is: $\mathrm{HOMA}-\mathrm{IR}=\mathrm{FBS} \times$ fasting insulin/405.

\subsection{Evaluation of Liver Diseases}

Anti-HCV was measured using a chemiluminescent enzyme immunoassay kit (Lumipulse II HCV, Fujirebio; Tokyo, Japan). HCV RNA was analyzed in serum by quantitative PCR assay (COBAS AMPLICOR HCV MONITOR v 2.0 Test, COBAS AmpliPrep/COBAS Taq-Man HCV Test; Roche Molecular Systems, New Jersey, the US) (21, 22). HCV genotype was determined by polymerase chain reaction assay, using a mixture of primers for the subtype, as reported previously (23). Ultrasonographic examination was performed for all patients to investigate the shape of liver and its lesions. Computed tomography was also performed for some patients. We used other possible predictors of progression of liver cirrhosis (LC), including serum Alb, T.Bil, prothrombin time and Plt.

\subsection{Evaluation of Extrahepatic Diseases}

Diagnosis of type II DM was based on the American Diabetic Association (ADA) criteria of 1997. Hypertension was defined as a systolic blood pressure (SBP) of $140 \mathrm{mmHg}$ or higher or a diastolic blood pressure (DBP) of $90 \mathrm{mmHg}$ or higher, according to the criteria of JNC-VI of the International Hypertension Society. FT3, FT4 and thyroid stimulating hormone (TSH) were measured for all patients and thyroid sonography examination was performed for some. Examination of upper or lower gastrointestinal tract was performed for patients for whom it was deemed clinically necessary.

\subsection{Detection of P. gingivalis fimA Genotypes in 28 Patients (Study 2)}

Analysis of P. gingivalis, Aggregatibacter actinomycetemcomitans (A. actinomycetemcomitans), P. intermedia, T. forsythensis, Treponema denticol (T. denticol) and Fusobacterium necrophorum (F. necrophorum) bacteria was conducted by a clinical laboratory test company using a PCR-Invader assay (BML Inc., Tokyo, Japan) (24). P. gingivalis with fimA genotype types I to $\mathrm{V}$ was detected in 28 saliva specimens.

\subsection{Ethical Considerations}

The investigation was explained to all participants. The study was conducted in full accordance with the ethical principles of the World Medical Association Declaration of Helsinki.

Study 1, The Ethical Committee of Kurume University concluded that this retrospective study was not included in the ethics guidelines, because it was a medical practice involving diagnosis and treatment. Study 2, The study protocol was approved by the Ethics Committee of $\mathrm{Ku}$ rume University (reference number:12240) in accordance with the Declaration of Helsinki. A written informed consent was obtained from each patient.

\subsection{Statistical Analysis}

All data were expressed as mean \pm standard error. Differences between the two groups were analyzed using Mann-Whitney U test, Wilcoxon's test and the Fisher's exact test. Differences were significant at $\mathrm{P}<0.05$ (twotailed). Adjusted odds ratios were calculated using logistic regression analysis. All statistical analyses were conducted using JMP Version 11.1.1 software (SAS Institute, Cary, NC, USA). The level of statistical significance was defined as $\mathrm{P}<0.05$.

\section{Results}

\subsection{Characteristics of 351 Patients in Study 1}

In total, 351 patients aged 17 to 87 years, with an average age of $60.62 \pm 11.26$ years (Table 1 ) were recruited. 147 were men and 204 women. The liver disease in study 1 included acute hepatitis $\mathrm{C}(\mathrm{n}=1,0.28 \%)$, chronic hepatitis $\mathrm{C}(\mathrm{CH}-\mathrm{C})$ ( $n=156,44.44 \%), \mathrm{CH}-\mathrm{C}$ and fatty liver $(n=6,1.71 \%), \mathrm{CH}-\mathrm{C}$ and HCC ( $n=15,4.27 \%), C H-C$ and alcoholic liver disease $(n=3$, $0.85 \%), \mathrm{CH}-\mathrm{C}$ and autoimmune hepatitis $(\mathrm{n}=2,0.57 \%)$, past history of HCV infection ( $\mathrm{n}=1,0.28 \%$ ), CH-C during IFN ( $\mathrm{n}$ $=66,18.80 \%)$, CH-C during IFN and fatty liver $(n=1,0.28 \%)$, $\mathrm{CH}-\mathrm{C}$ during IFN, alcoholic liver disease $(\mathrm{n}=2,0.57 \%), \mathrm{CH}-\mathrm{C}$ during IFN, post HCV-related HCC $(n=3,0.85 \%)$, CH-C post IFN (sustained virological response, $\operatorname{SVR})(\mathrm{n}=23,6.55 \%)$, $\mathrm{CH}-\mathrm{C}$ post IFN (SVR) and fatty liver $(\mathrm{n}=2,0.57 \%)$, $\mathrm{CH}-\mathrm{C}$ post IFN (SVR) and NAFLD ( $\mathrm{n}=1,0.28 \%), \mathrm{CH}-\mathrm{C}$ post IFN (SVR) and post HCV-related HCC ( $\mathrm{n}=2,0.57 \%), \mathrm{CH}-\mathrm{C}$ post IFN (SVR) and asymptomatic HBV carrier $(\mathrm{n}=1,0.28 \%)$, liver cirrhosis type C (LC-C) ( $n=10,2.85 \%)$, LC-C and HCC ( $n=21,5.98 \%)$, LC-C and HCC with autoimmune hepatitis $(n=1,0.28 \%)$, LC-C during IFN ( $\mathrm{n}=13,3.70 \%)$, LC-C during IFN and post HCV-related HCC ( $n=2,0.57 \%)$, LC-C post IFN (SVR) $(n=4$, $1.14 \%), \mathrm{CH}-\mathrm{C}$ and $\mathrm{B}$ and HCC $(\mathrm{n}=2,0.57 \%)$, asymptomatic HBV carrier ( $n=1,0.28 \%)$, chronic hepatitis $B(n=6,1.71 \%)$, chronic hepatitis $B$ and fatty liver $(n=1,0.28 \%)$, chronic hepatitis B during IFN $(n=1,0.28 \%)$, LC type B $(n=2,0.57 \%)$, LC type B and CH-C during IFN $(n=1,0.28 \%)$ and a past history of HBV infection ( $n=1,0.28 \%$ ). Complications are shown in Table 1 . The results of salivary occult blood testing were as follows: double positive/++, $\mathrm{n}=76$; positive/+, $\mathrm{n}=181$ and negative $/-, \mathrm{n}=94$. We compared characteristics of 76 patients (group 1) who had a strong positive result for salivary occult blood test and 275 patients (group 2) with a weak positive or negative result.

\subsection{Factors Associated with a Positive Result for Salivary Occult Blood Test According to Univariate Analysis (study 1)}

Univariate analyses demonstrated significant associations between group 1 and group 2 (Table 1). Significant 
Nagao Yetal.

\begin{tabular}{|c|c|c|c|c|}
\hline & Patients' Data & $\begin{array}{c}\text { Strong positive } \\
(\text { Group 1) }(n=76)\end{array}$ & $\begin{array}{l}\text { Weak positive or nega- } \\
\text { tive (Group } 2)(n=275)\end{array}$ & PValue \\
\hline Gender, No. & & & & NS \\
\hline Male & 147 & 39 & 108 & \\
\hline Female & 204 & 37 & 167 & \\
\hline Age, $y^{b}$ & $60.62 \pm 11.26$ & $62.36 \pm 10.07$ & $60.14 \pm 11.53$ & NS \\
\hline BMI, $\mathrm{kg} / \mathrm{m}^{2} \mathrm{~b}$ & $22.78 \pm 3.29$ & $23.95 \pm 3.72$ & $22.46 \pm 3.09$ & 0.0003 \\
\hline AST, $\mathbf{U} / \mathbf{I}^{\mathrm{b}}$ & $48.93 \pm 33.80$ & $60.41 \pm 37.35$ & $45.76 \pm 32.11$ & 0.0003 \\
\hline $\mathbf{A L T}, \mathbf{U} / \mathbf{I}^{\mathrm{b}}$ & $50.99 \pm 41.92$ & $61.24 \pm 43.53$ & $48.16 \pm 41.10$ & 0.0021 \\
\hline $\mathbf{L D H}, \mathbf{U} / \mathbf{I}^{\mathrm{b}}$ & $198.89 \pm 43.37$ & $208.63 \pm 49.22$ & $196.17 \pm 41.28$ & 0.0171 \\
\hline $\mathbf{A L P}, \mathbf{U} / \mathbf{l}^{\mathrm{b}}$ & $295.76 \pm 139.29$ & $354.23 \pm 190.97$ & $279.48 \pm 116.38$ & 0.0005 \\
\hline T.pro, g/dL ${ }^{b}$ & $7.60 \pm 0.56$ & $7.69 \pm 0.52$ & $7.58 \pm 0.57$ & 0.0549 \\
\hline Alb, $g / d_{L}{ }^{b}$ & $4.15 \pm 0.45$ & $4.02 \pm 0.44$ & $4.18 \pm 0.44$ & 0.0018 \\
\hline D.Bil, mg/dL ${ }^{b}$ & $0.12 \pm 0.12$ & $0.18 \pm 0.20$ & $0.10 \pm 0.08$ & 0.0003 \\
\hline FBS, $\mathbf{m g} / \mathbf{d L}^{\mathrm{b}}$ & $105.50 \pm 21.94$ & $108.69 \pm 26.84$ & $104.63 \pm 20.37$ & NS \\
\hline T.cho, mg/dL ${ }^{b}$ & $173.18 \pm 35.52$ & $164.77 \pm 32.85$ & $175.45 \pm 35.93$ & 0.0316 \\
\hline HbA1c, \% ${ }^{b}$ & $5.43 \pm 0.69$ & $5.45 \pm 0.79$ & $5.42 \pm 0.67$ & NS \\
\hline AFP, $n g / d^{b}{ }^{b}$ & $23.13 \pm 176.28$ & $63.42 \pm 371.08$ & $11.79 \pm 29.98$ & $<0.0001$ \\
\hline Plt, $\times 104 / \mu L^{b}$ & $14.91 \pm 5.11$ & $12.91 \pm 4.64$ & $15.46 \pm 5.11$ & 0.0003 \\
\hline WBC, $\mu \mathrm{L}^{\mathrm{b}}$ & $4642.61 \pm 1453.08$ & $4568.00 \pm 1479.51$ & $4663.03 \pm 1447.83$ & NS \\
\hline $\mathbf{H b}, \mathbf{g} / \mathbf{d L}^{\mathrm{b}}$ & $13.70 \pm 1.63$ & $13.65 \pm 1.66$ & $13.72 \pm 1.63$ & NS \\
\hline IRI, $\mu \mathrm{U} / \mathbf{m L}^{\mathrm{b}}$ & $14.15 \pm 15.98$ & $17.13 \pm 20.23$ & $13.31 \pm 14.48$ & 0.0071 \\
\hline HOMA-IR ${ }^{\text {b }}$ & $3.77 \pm 4.89$ & $4.87 \pm 7.03$ & $3.45 \pm 4.02$ & 0.0036 \\
\hline $\mathrm{CRP}, \mathrm{mg} / \mathrm{dL}^{\mathrm{b}}$ & $0.09 \pm 0.16$ & $0.08 \pm 010$ & $0.09 \pm 0.18$ & NS \\
\hline $\mathrm{Zn}, \mu \mathrm{g} / \mathbf{d L}^{\mathrm{b}}$ & $72.14 \pm 14.83$ & $71.34 \pm 15.92$ & $72.36 \pm 14.54$ & NS \\
\hline Anti-HCV, positive \% & $340(96.87)$ & $75(98.68)$ & $265(96.36)$ & NS \\
\hline HBsAg, positive \% & $9(2.56)$ & $0(0)$ & $9(3.27)$ & NS \\
\hline Current IFN treatment, positive \% & $89(25.36)$ & $30(39.47)$ & $59(21.45)$ & 0.0014 \\
\hline \multicolumn{5}{|l|}{ Liver diseases } \\
\hline HCC or post HCC & $49(13.96)$ & $14(18.42)$ & $35(12.73)$ & NS \\
\hline LC & $54(15.38)$ & $17(22.37)$ & $37(13.45)$ & 0.0566 \\
\hline \multicolumn{5}{|l|}{ Extrahepatic manifestations } \\
\hline Lichen planus, positive & $51(14.53)$ & $11(14.47)$ & $40(14.55)$ & NS \\
\hline Extrahepatic malignant tumor, positive & $27(7.69)$ & $4(5.26)$ & $23(8.36)$ & NS \\
\hline Diabetes mellitus, positive & $59(16.81)$ & $17(22.37)$ & $42(15.27)$ & NS \\
\hline Hypertension, positive & $103(29.34)$ & $25(32.89)$ & $78(28.36)$ & NS \\
\hline Heart disease, positive & $14(3.99)$ & $4(5.26)$ & $10(3.64)$ & NS \\
\hline Sjogren's syndrome, positive & $4(1.14)$ & $1(1.32)$ & $3(1.09 \%)$ & NS \\
\hline Thyroid disease, positive & $18(5.13)$ & $6(7.89)$ & $12(4.36)$ & NS \\
\hline Osteoporosis, positive & $13(3.70)$ & $1(1.32)$ & $12(4.36)$ & NS \\
\hline Others, positive & $79(22.51)$ & $17(22.37)$ & $62(22.55)$ & NS \\
\hline \multicolumn{5}{|l|}{ Brushing teeth } \\
\hline Twice or more a day & $281(80.06)$ & $50(65.79)$ & $231(84.00)$ & 0.0004 \\
\hline Only once a day & $61(17.38)$ & $25(32.89)$ & $36(13.09)$ & $<0.0001$ \\
\hline Smoking history, yes & $168(47.86)$ & $43(56.58)$ & $125(45.45)$ & NS \\
\hline History of alcohol intake, yes & $174(49.57)$ & $39(51.32)$ & $135(49.09)$ & NS \\
\hline Subjective symptom of taste disorder, positive & $16(4.56)$ & $1(1.32)$ & $15(5.45)$ & NS \\
\hline
\end{tabular}


factors for groups were obesity $(\mathrm{P}=0.0003)$, AST $(\mathrm{P}=$ 0.0003), $\operatorname{ALT}(\mathrm{P}=0.0021), \operatorname{LDH}(\mathrm{P}=0.0171), \operatorname{ALP}(\mathrm{P}=0.0005)$, Alb ( $P=0.0018)$, D.Bil $(P=0.0003)$, T.cho $(P=0.0316)$, AFP $(\mathrm{P}<0.0001), \mathrm{Plt}(\mathrm{P}=0.0003), \operatorname{IRI}(\mathrm{P}=0.0071)$, HOMA-IR $(\mathrm{P}=$ $0.0036)$, current IFN treatment $(\mathrm{P}=0.0014)$ and daily frequency of tooth brushing $(\mathrm{P}<0.0001)$. Between the two groups, T.pro level and liver fibrosis were significant factors. There were no significant differences in the levels of FBS, HbA1c, WBC, Hb, CRP, Zn, presence of HCC and extrahepatic manifestations, history of smoking and alcohol intake and taste disorder between the two groups.

\subsection{Multivariate Analysis (study 1)}

All variables in the univariate analyses were included in the multivariate analysis (Table 2). According to multivariate analysis, five factors were associated with a strong positive result for salivary occult blood test, suggestive of the presence of periodontal disease: i.e. Plt count below 80000 , brushing teeth only once a day, current IFN treatment, aged 65years or older and obesity (BMI $\geq 25 \mathrm{~kg} / \mathrm{m}^{2}$ ). The adjusted odds ratios for these five factors were 5.80 , $3.46,2.87,2.50$ and 2.33, respectively, and each was statistically significant.

\subsection{Prevalence of fimA Genotype Among HCV-In- fected Patients}

Among 28 patients, 14 had only hepatitis C (group A), and 14 had LC or a history of HCC treatment (group B) (Table 3). The prevalence of fimA genotype II was higher in group B (50.00\%) than group A (21.43\%).

\section{Discussion}

HCC is one of the most common forms of malignancy, particularly in Japan. The most important risk factors of HCC are chronic hepatitis C and B and cirrhosis. Japanese patients with chronic hepatitis $\mathrm{C}$ are generally treated with IFN, but an additional strategy for preventing HCC development is urgent need for LC patients. In our retrospective analysis, we found an association between periodontitis and IFN therapy. We previously reported that dental problems delayed the initiation of IFN therapy for HCV-infected patients (25). HCV-infected patients treated with IFN therapy should be managed by intensive oral care because of lowered resistance to infection during the therapy. Regarding a potential link between periodontal diseases and liver fibrosis in patients with HCVand/or HBV-related liver diseases, patients with a strong positive result for salivary occult blood test, indicative of periodontal disease, had a higher prevalence of indices associated with liver disease progression (e.g. elevated AFP level, thrombocytopenia, hypoalbuminemia and hyperbilirubinemia) compared to patients with slight or no periodontitis. Moreover, the prevalence of fimA genotype II was higher in patients with LC (50.00\%) than those with only hepatitis C (21.43\%). In summary, our results showed a possible association between periodontitis and progression of viral liver disease. We found obesity as a risk factor of periodontal disease among patients with viral liver disease. The meta-analysis showed a significant association between obesity and periodontitis ( $\mathrm{OR}=1.30[95 \%$ Confidence Interval (CI), 1.25 - 1.35]) and between mean BMI and periodontal disease (mean difference $=2.75$ ) (26). Obesity, a key component of metabolic syndrome, has been linked to a higher frequency of cancers in a variety of tissues including the liver (27). Potential mediators of obesity-related HCC include lipotoxicity, changes in the gut microbiome, an imbalance in proinflammatory/antiinflammatory cytokines, stimulation of insulin-like growth factor 1 (IGF-1) axis by hyperinsulinemia, reduced adiponectin secretion and increased leptin levels. Patients with periodontitis had a significantly lower frequency of tooth brushing. Joint support involving a dentist, a primary care physician and particularly a hepatologist is necessary for patients with liver disease to appreciate the importance of good oral hygiene.

Table 2. Factors Associated With a Strong Positive Result for Salivary Occult Blood Test According to Multivariate Analysis ${ }^{a}$

\begin{tabular}{lccc}
\hline & Odds Ratio & 95\% CI & PValue \\
\hline PLT $<\mathbf{8 . 0}, \times \mathbf{1 0}^{\mathbf{4}} / \boldsymbol{\mu L}$ & 5.80 & {$[2.30,14.92]$} & 0.0002 \\
$\begin{array}{l}\text { Brushing teeth only } \\
\text { once a day }\end{array}$ & 3.46 & {$[1.78,6.76]$} & 0.0003 \\
Current IFN treatment & 2.87 & {$[1.52,5.43]$} & 0.0012 \\
65 years or older & 2.50 & {$[1.37,4.63]$} & 0.0028 \\
Obesity, BMI $\geq \mathbf{2 5} \mathbf{~ k g / \mathbf { m } ^ { 2 }}$ & 2.33 & {$[1.22,4.39]$} & 0.0103 \\
\hline a Abbreviation: PLT, platelets. & & &
\end{tabular}

Table 3. Prevalence of fim A Genotype Among HCV-Infected Patients $(\mathrm{n}=14)^{\mathrm{a}}$

\begin{tabular}{lccc}
\hline & $\begin{array}{c}\text { Only CH-C } \\
\text { Group A }\end{array}$ & $\begin{array}{c}\text { LC or HCC } \\
\text { Group B }\end{array}$ & P Value \\
\hline Gender & 5 & 11 & 0.0219 \\
Male & 9 & 3 & \\
\hline Female & $70.79 \pm 5.28$ & $69.15 \pm 10.80$ & NS \\
Age, $\mathbf{P}$ & & & \\
P.gingivalisfimA & $3(21.43)$ & $3(21.43)$ & NS \\
Genotype I & $0(0.00)$ & $1(7.14)$ & NS \\
\hline Genotype I and II & $3(21.43)$ & $7(50.00)$ & NS \\
Genotype II & $1(7.14)$ & $0(0.00)$ & NS \\
\hline Genotype III & $2(14.29)$ & $0(0.00)$ & NS \\
\hline Genotype IV & $0(0.00)$ & $1(7.14)$ & NS \\
\hline Genotype V & $5(35.71)$ & $2(14.29)$ & NS \\
\hline $\begin{array}{l}\text { Below detection sensitiv- } \\
\text { ity limits }\end{array}$ & & & \\
\hline a Data are presented as No.(\%) or Mean \pm SD. & & \\
\hline
\end{tabular}


Currently, in Japan, no such support system exists. Several studies showed an association between HCV infection and insulin resistance $(28,29)$, and severe periodontal disease is known to cause insulin resistance (30). Problems faced by HCV-infected individuals regarding oral healthcare may be due to decreased salivary flow rate, elicitation of periodontal disease by insulin resistance and difficulties with radical dental treatment for patients with liver disease, because of complications such as prolonged bleeding. Henderson and colleagues reported that HCVinfected patients may sometimes face discrimination by practitioners (31). The role of oral fluid on periodontal condition of patients with viral hepatitis is unknown. However, HBV and HCV markers in gingival crevicular fluid (GCF) have been studied. GCF, a serum transudate or inflammatory exudate, can be collected from gingival crevice surrounding the teeth. GCF contains microbial plaque, host inflammatory cells, host tissue and serumderivers factors (32). Hepatitis B surface antigen (HBsAg) was detected in GCF and whole saliva in approximately 90\% of samples from seropositive patients, implying that GCF is likely the source of HBsAg in saliva (33). Anti-HCV antibodies and HCV RNA were also detected in GCF and saliva of HCV-positive patients (34-36). These data support the concept that GCF may be a significant source of hepatitis virus in saliva. AST is an enzyme found at increased concentrations in red blood cells, liver, heart and muscles. Persson et al. demonstrated that AST levels can be used to assess the presence and extent of periodontal inflammation (37). Median AST levels were significantly higher for the sites experiencing clinical attachment loss in comparison to sites not experiencing attachment loss. Further studies are needed to clarify the association between inflammatory substances in GCF and viral hepatitis. Liver fibrosis can increase the risk of periodontal diseases, which are more prevalent among elderly. The prevalence of periodontal disease among HCV-infected patients in Japan would be expected to increase. Similarly, in Japan the number of older patients with HCV is increasing. A cooperative system to help minimize the impact of periodontitis on the progression of liver disease is urgently needed. In conclusion, our retrospective analysis showed that periodontitis might be associated with progression of viral liver disease; therefore, controlling oral disease is essential for prevention and management of liver fibrosis.

\section{Acknowledgements}

This study was supported in part by a Grant-in-Aid for Scientific Research (C) (No.25463274) from the Ministry of Education, Culture, Sports, Science and Technology of Japan.

\section{Authors' Contributions}

Yumiko Nagao performed most of data collection, designed the study, performed the statistical analysis and drafted the manuscript. Yuji Kawahigashi provided comments during manuscript preparation. Michio Sata contributed to data collections and clinical diagnosis. All authors read and approved the final version of the manuscript.

\section{Finding/Support}

This study was supported in part by a Grant-in-Aid for Scientific Research (C) (No.25463274) from the Ministry of Education, Culture, Sports, Science and Technology of Japan.

\section{References}

1. Umemura T, Ichijo T, Yoshizawa K, Tanaka E, Kiyosawa K. Epidemiology of hepatocellular carcinoma in Japan. J Gastroenterol. 2009;44 Suppl 19:102-7.

2. Kiyosawa K, Umemura T, Ichijo T, Matsumoto A, Yoshizawa K, Gad A, et al. Hepatocellular carcinoma: recent trends in Japan. Gastroenterology. 2004;127(5 Suppl 1):S17-26.

3. Asahina Y, Tsuchiya K, Tamaki N, Hirayama I, Tanaka T, Sato M, et al. Effect of aging on risk for hepatocellular carcinoma in chronic hepatitis C virus infection. Hepatology. 2010;52(2):518-27.

4. Yoshida H, Shiratori Y, Moriyama M, Arakawa Y, Ide T, Sata M, et al Interferon therapy reduces the risk for hepatocellular carcinoma: national surveillance program of cirrhotic and noncirrhotic patients with chronic hepatitis C in Japan. IHIT Study Group. Inhibition of Hepatocarcinogenesis by Interferon Therapy. Ann Intern Med.1999;131(3):174-81.

5. Yoshida H, Arakawa Y, Sata M, Nishiguchi S, Yano M, Fujiyama S, et al. Interferon therapy prolonged life expectancy among chronic hepatitis C patients. Gastroenterology. 2002;123(2):483-91.

6. Yamasaki K, Tomohiro M, Nagao Y, Sata M, Shimoda T, Hirase K, et al. Effects and outcomes of interferon treatment in Japanese hepatitis C patients. BMC Gastroenterol. 2012;12:139.

7. Beck J, Garcia R, Heiss G, Vokonas PS, Offenbacher S. Periodontal disease and cardiovascular disease. J Periodontol. 1996;67(10 Suppl):1123-37.

8. Mealey BL, Oates TW, American Academy of P. Diabetes mellitus and periodontal diseases. J Periodontol. 2006;77(8):1289-303.

9. Lopez NJ, Smith PC, Gutierrez J. Higher risk of preterm birth and low birth weight in women with periodontal disease. J Dent Res. 2002;81(1):58-63.

10. Bascones-Martinez A, Figuero-Ruiz E. Periodontal diseases as bacterial infection. Med Oral Patol Oral Cir Bucal. 2004;9 Suppl:101-7.

11. Kolenbrander PE, Andersen RN, Blehert DS, Egland PG, Foster JS, Palmer RJ. Communication among Oral Bacteria. Microbiol Mol Biol Rev. 2002;66(3):486-505.

12. Ishihara K, Nabuchi A, Ito R, Miyachi K, Kuramitsu HK, Okuda K Correlation between Detection Rates of Periodontopathic Bacterial DNA in Carotid Coronary Stenotic Artery Plaque and in Dental Plaque Samples. J Clin Microbiol. 2004;42(3):1313-5.

13. Socransky SS, Haffajee AD, Cugini MA, Smith C, Kent RL. Microbial complexes in subgingival plaque. J Clin Periodontol. 1998;25(2):134-44.

14. Nakagawa I. Functional Differences among FimA Variants of Porphyromonas gingivalis and Their Effects on Adhesion to and Invasion of Human Epithelial Cells. Infect Immun. 2002;70(1):277-85.

15. Amano A, Nakagawa I, Kataoka K, Morisaki I, Hamada S. Distribution of Porphyromonas gingivalis strains with fimA genotypes in periodontitis patients. J Clin Microbiol. 1999;37(5):1426-30.

16. Missailidis CG, Umeda JE, Ota-Tsuzuki C, Anzai D, Mayer MP. Distribution of fimA genotypes of Porphyromonas gingivalis in subjects with various periodontal conditions. Oral Microbiol Immunol. 2004;19(4):224-9.

17. Yoneda M, Naka S, Nakano K, Wada K, Endo H, Mawatari H, et al. Involvement of a periodontal pathogen, Porphyromonas gingivalis on the pathogenesis of non-alcoholic fatty liver disease. BMC Gastroenterol. 2012;12:16. 


\section{Nagao Yetal.}

18. Hashimoto M, Yamanaka K, Shimosato T, Ozawa A, Takigawa T, Hidaka S, et al. Oral condition and health status of elderly 8020 achievers in Aichi Prefecture. Bull Tokyo Dent Coll. 2006;47(2):37-43.

19. Niwa M, Fukuda M. Clinical study on the control of dental plaque using a photo energy conversion toothbrush equipped with a TiO2 semiconductor. Shigaku. 1989;77(2):598-606.

20. Kaufman E, Lamster IB. Analysis of saliva for periodontal diagnosis--a review. J Clin Periodontol. 2000;27(7):453-65.

21. Lee SC, Antony A, Lee N, Leibow J, Yang JQ, Soviero S, et al. Improved version 2.0 qualitative and quantitative AMPLICOR reverse transcription-PCR tests for hepatitis C virus RNA: calibration to international units, enhanced genotype reactivity, and performance characteristics. J Clin Microbiol. 2000;38(11):4171-9.

22. Sizmann D, Boeck C, Boelter J, Fischer D, Miethke M, Nicolaus S, et al. Fully automated quantification of hepatitis C virus (HCV) RNA in human plasma and human serum by the COBAS AmpliPrep/ COBAS TaqMan system. J Clin Virol. 2007;38(4):326-33.

23. Dusheiko G, Schmilovitz-Weiss H, Brown D, McOmish F, Yap PL, Sherlock S, et al. Hepatitis $C$ virus genotypes: an investigation of type-specific differences in geographic origin and disease. Hepatology. 1994;19(1):13-8.

24. Tadokoro K, Yamaguchi T, Kawamura K, Shimizu H, Egashira T, Minabe M, et al. Rapid quantification of periodontitis-related bacteria using a novel modification of Invader PLUS technologies. Microbiol Res. 2010;165(1):43-9.

25. Nagao Y, Sata M. Dental problems delaying the initiation of interferon therapy for HCV-infected patients. Virol J. 2010;7:192.

26. Moura-Grec PG, Marsicano JA, Carvalho CA, Sales-Peres SH. Obesity and periodontitis: systematic review and meta-analysis. Cien Saude Colet. 2014;19(6):1763-72.

27. El-Serag HB, Kanwal F. Obesity and hepatocellular carcinoma: hype and reality. Hepatology. 2014;60(3):779-81.

28. Serfaty L, Capeau J. Hepatitis C, insulin resistance and diabetes: clinical and pathogenic data. Liver Int. 2009;29 Suppl 2:13-25.

29. Nagao Y, Kawasaki K, Sata M. Insulin resistance and lichen planus in patients with HCV-infectious liver diseases. J Gastroenterol Hepatol. 2008;23(4):580-5.

30. Nishimura F, Murayama Y. Periodontal inflammation and insulin resistance-lessons from obesity. J Dent Res. 2001;80(8):1690-4.

31. Henderson L, Muir M, Mills PR, Spence E, Fox R, McCruden EA, et al. Oral health of patients with hepatitis $C$ virus infection: a pilot study. Oral Dis. 2001;7(5):271-5.

32. Embery G, Waddington R. Gingival crevicular fluid: biomarkers of periodontal tissue activity. Adv Dent Res.1994;8(2):329-36.

33. Ben-Aryeh H, Ur I, Ben-Porath E. The relationship between antigenaemia and excretion of hepatitis B surface antigen in human whole saliva and in gingival crevicular fluid. Arch Oral Biol. 1985;30(1):97-9.

34. Montebugnoli L, Dolci G. Anti-HCV antibodies are detectable in the gingival crevicular fluid of HCV positive subjects. Minerva Stomatol. 2000;49(1-2):1-8.

35. Maticic M, Poljak M, Kramar B, Seme K, Brinovec V, Meglic-Volkar $\mathrm{J}$, et al. Detection of hepatitis $\mathrm{C}$ virus RNA from gingival crevicular fluid and its relation to virus presence in saliva.J Periodontol. 2001;72(1):11-6.

36. Nagao Y, Seki N, Tamatsukuri S, Sata M. Detection of hepatitis C virus in saliva before and after scaling of dental calculus. Kansenshogaku Zasshi. 2000;74(11):961-5.

37. Persson GR, DeRouen TA, Page RC. Relationship between gingival crevicular fluid levels of aspartate aminotransferase and active tissue destruction in treated chronic periodontitis patients. $J$ Periodontal Res.1990;25(2):81-7. 